London

Cite this as: $B M J$ 2021;373:n1415 http://dx.doi.org/10.1136/bmj.n1415 Published: 02 June 2021

\title{
Covid-19: Official figures "underestimate" deaths caused by discharging patients into care homes
}

\section{Adrian O'Dowd}

The UK government has admitted that its policy during the early stages of the covid-19 pandemic to have patients moved from hospitals to care homes may have directly led to subsequent deaths.

Outbreaks of the virus could potentially be linked to the policy, says a report from Public Health England (PHE), ${ }^{1}$ because patients were not always tested for covid before being moved, a requirement that was introduced only in mid-April last year.

Experts say that the report is limited, however, in terms of what it measured and that it probably significantly underestimates the policy's impact on deaths in care homes.

The PHE report was published the day after the prime minister's former chief adviser, Dominic Cummings, criticised the government's handling of the pandemic at a parliamentary select committee evidence session he addressed on 26 May. ${ }^{23}$ Among other accusations, Cummings questioned an assertion made at the time by England's health secretary, Matt Hancock, that the government had "tried to throw a protective ring" around care homes.

The PHE report said its findings suggested that hospital associated seeding accounted for only a small proportion of all outbreaks in care homes. It said that from 30 January to 12 October 2020 it identified 43398 (8.4\%) care home residents who tested positive for covid-19 with laboratory confirmation, and death was reported in 34\% (13795).

This analysis identified 97 care home outbreaks (1.6\%) from a total of 5882 outbreaks that were due to "hospital associated seeding," involving 804 care home residents and 286 (2.1\%) deaths.

Jenny Harries, chief executive of the UK Health Security Agency, said at a government covid press briefing last week that the study indicated that the policy of discharging hospital patients had had a limited impact on outbreaks in care homes. "This report showed that discharge from hospitals was actually a very, very tiny proportional cause of cases: $1.6 \%$ of all care home outbreaks," she said.

However, experts have questioned this interpretation.

\section{Narrow question}

Adelina Comas-Herrera, a researcher at the London School of Economics and Political Science's Care Policy and Evaluation Centre, told The BMJ, "The report deals with a very narrow question: what is the number of people who can be almost directly identified as potentially having brought covid to a care home. I don't think it brings a full answer to the question of how many people may have died as a result of infection. It tells us who has been identified but not the scale of the problem.

“An important caveat on data from the earlier part of the pandemic is that it included only people who had been tested, while there were important constraints to testing in care homes at that time."

Comas-Herrera argued that the Office for National Statistics' estimates for England and Wales had shown that during a key part of this period (March-May 2020) nearly 40\% excess deaths of people in care homes occurred that had not been attributed to covid-usually due to not having been tested or not having been recognised when recording the death as attributed to covid.

She added, "There is nothing wrong with the PHE report, but it doesn't give the full picture because, at that time, there was very limited testing capability in care homes."

Adam Gordon, president elect of the British Geriatrics Society, told The BMJ that the report's shortcomings included the fact that around $10 \%$ of covid cases in care homes were unmatched because of a lack of available address data.

"Probably the most significant limitation is that the study depended on residents having a positive covid test to determine an outbreak, and we know that such testing was limited and inconsistent during March and the first part of April," he said. "These are the months during which most seeding was reported to have taken place.

"The level of seeding reported is likely to be an underestimate, and I would tend to take the report as confirmation that seeding from hospital occurred and is likely to have been one of several factors that contributed to the catastrophic care home outbreaks we saw during the first wave. The report almost certainly underestimates the magnitude of this."

Other reports have suggested more detail on the scale of the problem. Last week the independent charity the Health Foundation said that 27179 excess deaths had occurred among care home residents since the start of the pandemic, representing a $20 \%$ increase on recent years, and 9571 excess deaths were reported among people receiving domiciliary care since 11 April 2020, a 62\% increase. ${ }^{4}$

The authors said that central government support for social care in England during the first wave of the pandemic had been "too slow and limited," with inadequate protection for people using and providing care. 


\section{Lack of testing}

Sarah Scobie, deputy director of research for the Nuffield Trust think tank, told The BMJ that it was difficult to estimate the deaths in care homes among people transferred from hospital.

"There were lots of factors that could be involved in the high death toll: access to personal protective equipment, the difficulty of isolating infected patients within a care home environment, and staff working across multiple care homes," she told The BMJ. "It is also important to note that the PHE analysis doesn't include people who weren't care home residents prior to their admission."

David Oliver, NHS consultant geriatrician and a BMJ columnist, said, "I worked as a doctor on covid wards throughout both pandemic surges and am in no doubt that, in spring 2020, there was such a shortage of testing capacity that some patients were discharged to care homes untested or with positive tests. The written national policy enabling this is a matter of record and was only changed in mid-April, at which time the practice largely ceased.”

Oliver, who is also former president of the British Geriatrics Society, added, "It was always doubtful that all the care home outbreaks resulted just from hospital discharges. This was a simplistic narrative, and outbreaks were seeded in other ways.

"However, I do think our initial lack of testing capacity showed a failure of planning, and to have a discharge policy that did not involve the care home sector or social care experts was a major mistake which should not be repeated in the future."

Martin McKee, professor of European public health at the London School of Hygiene \& Tropical Medicine and a member of Independent Sage (Scientific Advisory Group for Emergencies), told The BMJ, "The timing [of the report] is very strange. The date on the report is April 2021, but it was only issued at the end of May.

"A sentence in the conclusion suggests that it was written much earlier, likely in October 2020. Unfortunately, there have been recent concerns in the media about PHE's failure to publish data on transmission in schools. This might lead a cynic to question what seems like politically convenient timing, so, given the importance of trust in official data, PHE really needs to explain the delay."

Vic Rayner, chief executive of the National Care Forum, which represents not-for-profit care providers, added her criticism, saying, "The PHE report delivers an unhelpful analysis of data that provides, at best, a partial picture and, at worst, an unrecognisable representation of the impact that hospital discharge in the absence of testing had on the most vulnerable members of our society."

1 Public Health England. A data linkage approach to assessing the contribution of hospital-associated SARS-CoV-2 infection to care home outbreaks in England, 30 January to 12 October 2020. 27 May 2021. https://assets.publishing.service.gov.uk/government/uploads/system/uploads/attachment_data/file/983349/Data_linkage_approach_to_assessing_the_contribution_of_hospitalassociated_SARS-CoV-2_infection_to_care_home_outbreaks_in_England.pdf.

2 lacobucci G. Covid-19: PM's former chief aide accuses health secretary of lying over PPE and access to treatment. BMJ2021;373:n1369. doi: 10.1136/bmj.n1369 pmid: 34039614

3 lacobucci G. Covid-19: “Complete nonsense” to say government shielded care homes, says PM's former aide. BMJ2021;373:n1386. doi: 10.1136/bmj.n1386 pmid: 34049851

4 Health Foundation. Adult social care and COVID-19 after the first wave: assessing the policy response in England. May 2021. https://www.health.org.uk/publications/reports/adult-social-careand-covid-19-after-the-first-wave.

This article is made freely available for use in accordance with BMJ's website terms and conditions for the duration of the covid-19 pandemic or until otherwise determined by BMJ. You may use, download and print the article for any lawful, non-commercial purpose (including text and data mining) provided that all copyright notices and trade marks are retained. 